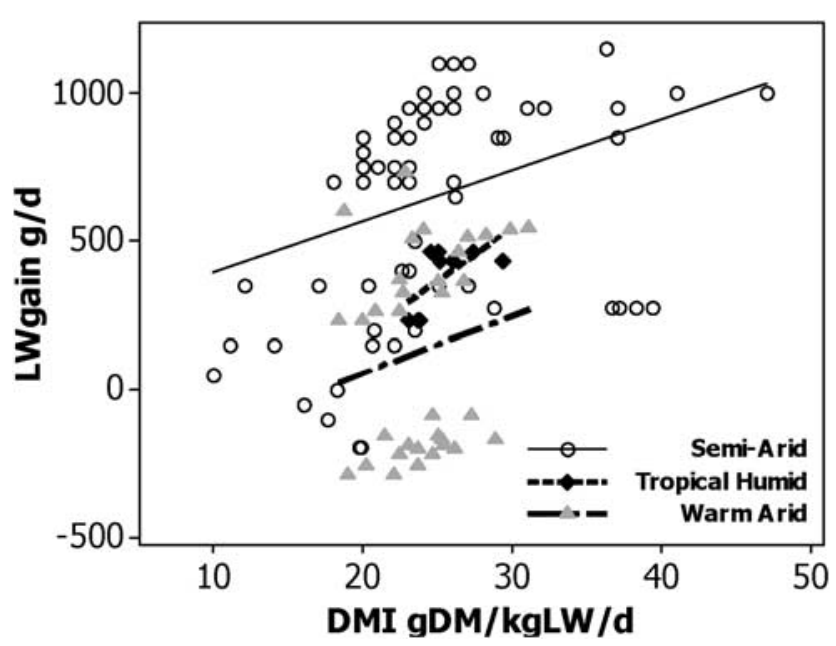

Fig. 1 Average daily gain variations for growing cattle related to DM intake levels in various climatic environments.

\title{
Conclusion
}

These preliminary results emphasize the influence of animal and environmental factors on average daily gains. Further analyses should now explore the influences of various climatic factors like temperatures, rainfall and photoperiod. Production levels of growing cattle appear to be well modulated by animals' management and, maybe even more, by nutrition. Measurements of vegetation structural features (biomass, allowance) do not seem to be major determinants of live weight gains. However, this result will have to be further analysed considering all the other papers giving ADG levels (without intake values). Moreover, pasture nutritional characteristics (nitrogen, fibre) should be integrated in future models. This work will contribute to a better understanding of ruminant production in the tropics and should offer the opportunity to identify appropriate strategies for animal management in tropical pastures.

\section{The evaluation of activated dietary charcoal from Canarium schweinfurthii Engl. seed and maize cob as a toxin binder in broiler chickens}

\author{
J. R. Kana ${ }^{\dagger}$, A. Teguia and J. Tchoumboue \\ Department of Animal Productions, Faculty of Agronomy and Agricultural Sciences, University of Dschang, P.O. Box 70 Dschang, Cameroon
}

\section{Aim}

One hundred and twenty 3-week old male broiler chickens were used to evaluate the effects of dietary charcoal from Canarium schweinfurthii (charcoal A) and maize cob (charcoal B) on aflatoxin $B_{1}$ toxicosis in broiler chickens.

\section{Materials \& Methods}

The individually caged birds were randomly allotted to 8 groups of 15 birds and fed in a completely randomised design a diet with either fresh groundnut meal $(C-)$, groundnut meal infested with $22.02 \mathrm{ppb}$ of aflatoxin $\mathrm{B}_{1}(\mathrm{C}+)$ or diet $\mathrm{C}+$ supplemented with either 0.2 or $0.4 \%$ of charcoal $A\left(A_{0.2}\right.$ and $A_{0.4}$ respectively), charcoal $B\left(B_{0.2}\right.$ and $B_{0.4}$ respectively) or a $1 / 1$ mixture of $A$ and $B\left(M_{0.2}\right.$ and $M_{0.4}$ respectively).

\section{Results}

The results indicated that the inclusion of charcoal either individually or as a mixture significantly $(P<0.05)$ improved feed intake (4166.66 to $4679.16 \mathrm{~g})$ as compared with that of birds fed diet $\mathrm{C}+(4075.00 \mathrm{~g})$. At $0.2 \%$ inclusion, the highest feed intake was recorded with the birds fed $\mathrm{M}_{0.2}(4679.16 \mathrm{~g})$ as compared with $\mathrm{A}_{0.2}, \mathrm{~B}_{0.21} \mathrm{C}-$ and $\mathrm{C}+$. In general, there was a drop in weight with increasing level of charcoal in the diet.

\footnotetext{
† E-mail: kanajean@yahoo.fr
} 
Birds fed diets $A_{0.2}, A_{0.4}$ and $M_{0.2}$ had a significantly $(P<0.05)$ higher live body weight and body weight gain when compared with all the other groups. The highest weight gain was recorded with birds fed the $1 / 1$ mixture of charcoal $A$ and $B$ at $0.2 \%$ inclusion in diet as compared with $0.4 \%$ inclusion. However, the inclusion of $0.2 \%$ charcoal $B$ and $0.4 \%$ of mixture in the diet significantly $(P<0.05)$ increased feed conversion ratio. Birds from treatments $\mathrm{C}+$ and $\mathrm{M}_{0.4}$ had smaller intestine weight and intestine density as compared with the birds from all other treatments. Carcass yield, relative weight of heart and abdominal fat were not significantly affected $(P>0.05)$ by the treatments. Both charcoal $A$ and $B$ significantly $(P<0.05)$ yielded smaller liver weight as compared with $C+$. The highest pancreas weight was recorded in birds fed C- $(0.20 \mathrm{~g})$ as compared with the birds fed any other diet $(0.13-0.18 \mathrm{~g})$.

\title{
Conclusion
}

It was concluded that up to $0.4 \%$ of maize cob charcoal and $0.2 \%$ of a $1 / 1$ mixture of charcoal from Canarium schweinfurthii seed and maize cob could be used as feed additive to absorb aflatoxin $\mathrm{B}_{1}$ and promote growth performance of broiler chickens.

\section{Tables of nutritive value for farm animals in tropical and Mediterranean regions: an important asset for improving the use of local feed resources}

\author{
Gilles $\operatorname{Tran}^{1 \dagger}$, Valérie Heuzé ${ }^{1}$, Denis Bastianelli ${ }^{2}$, Harry Archimède $^{3}$ and Daniel Sauvant ${ }^{4}$ \\ ${ }^{1}$ AFZ (Association Française de Zootechnie); ${ }^{2}$ CIRAD; ${ }^{3}$ INRA UR143, 97170 Petit Bourg, France; ${ }^{4}$ FZ\&UMR INRA-AgroParisTech MoSAR, France
}

\begin{abstract}
Introduction
The management of feed resources is of paramount importance and requires accurate feed values. Tables of feed composition and nutritive value are used to formulate diets that meet animal requirements at the lowest cost, thereby improving production results and farm productivity. In emerging and developing countries, and particularly those in tropical, subtropical and Mediterranean areas, the demand for animal products has been steadily growing in the past decades. There is thus a growing need for accurate feed information. However, even though many research data are published every year, they are rarely summarized in an easily available form, and users in these regions must often rely on data obtained in temperate countries or use obsolete or incomplete sources.

The Tables of nutritive values for farm animals in tropical and Mediterranean regions is a project of INRA (Institut national de la recherche agronomique), CIRAD (Centre de coopération internationale en recherche agronomique pour le développement) and AFZ (Association française de zootechnie), with partial support from the FAO and the help of other organisations. The project's goal is to produce comprehensive tables for feed users in these areas. The tables will include nutritional information for both conventional and non-conventional feed materials for the main livestock species. They are planned for release in 2013, either in paper or electronic form.
\end{abstract}

\section{Objectives}

The main objective is to create a compendium of up-to-date information on feed materials available to users in tropical, subtropical and Mediterranean regions. The project focuses on the following information:

Feed nomenclature and descriptions: names, physical aspect (including pictures), availability, processes and environmental impact.

Composition and nutritive values derived from feed databases and scientific literature.

Recommendations by livestock species, including cautionary information.

For local users, the benefits should be as follows:

- Better identification, qualification and quantification of local feed resources.

- Better awareness of potential synergies between local food industries and livestock production.

- Better use of local feed resources and less reliance on imported techniques and feed materials.

- In the near future, it will be also possible to use the tables' framework for quantitative environmental data.

For researchers, the tables should:

- Provide a comprehensive set of models of relationships between composition and nutrition parameters.

- Help to promote collaboration between teams working on tropical and Mediterranean animal feeding.

- Help to identify areas where knowledge is lacking so that experiments can be set up to generate new data.

- Promote research on biological response curves for animal production in the tropics.

\footnotetext{
† E-mail: gilles.tran@gmail.com
} 